\title{
POTENSI SUMBER DAYA PERIKANAN DI DANAU TOBA, SUMATERA UTARA
}

\author{
Didik Wahju Hendro Tjahjo*), Adriani Sri Nastiti"), Kunto Purnomo*), \\ Endi Setiadi Kartamihardja") dan Achmad S. Sarnita*)
}

\begin{abstract}
ABSTRAK
Perairan Danau Toba memerlukan teknologi pengelolaan sumber daya perikanan yang rasional dan berwawasan lingkungan. Tujuan penelitian ini yaitu mendapatkan data potensi perairan dan alternatif pengelolaan sumber daya perikanan di Danau Toba. Metode yang dipakai dalam penelitian ini adalah metode survai dengan pengambilan sampel strata, yang dilakukan pada musim hujan, kemarau dan pancaroba tahun 1994-1995. Parameter yang dianalisis adalah kualitas perairan, karakteristik populasi ikan dan cara pengelolaan sumber daya perikanan yang ada.

Hasil penelitian menunjukan bahwa kualitas perairan di Danau Toba masih cukup mendukung kehidupan dan perkembangan ikan maupun organisme pakannya. Akan tetapi perairan ini miskin unsur hara, curam, sangat dalam dan daerah litoralnya sangat sempit. Perairan ini dapat digolongkan ke dalam tipe perairan oligotrofik.

Berdasarkan karakteristik biologi ikan yang ada (kebiasaan makan, luas relung dan reproduksinya), kesuburan perairan dan morfometrik perairan, perairan ini kurang mendukung untuk usaha perikanan tangkap, walaupun pemerintah telah merehabilitasi stok ikan melalui restoking dan penetapan daerah reservat. Dengan demikian perlu alternatif pengembangan usaha perikanan lainnya yang lebih menguntungkan, yaitu usaha budidaya ikan dalam karamba jaring apung atau wisata perikanan.
\end{abstract}

ABSTRACT: Fisheries resource potential of Lake Toba, North Sumatera. By: D.W.H. Tjahjo, A.S. Nastiti, K. Purnomo, E.S. Kartamihardja, and A.S. Sarnita.

Toba Lake needs rational and environmental based technology for fisheries resource management. The aim of the study is to determine the pontential and management alternatives of the fisheries resource of Toba Lake. Method used in the study was a survey with stratification sampling, which was done during rainy, dry and transition season. Water quality, characteristics of fish population and the existing fisheries management were studied.

It was revealed that water quality of Toba Lake was still able to support fish life and its food organisms. However, the lake is poor in nutrient, deep, and having a steep shore with a narrow litoral zones. Based on these characteristics, the lake can be classified as an oligotrophic lake.

From the study on fish biology (food habit, niche breadth and reproduction), trophic level and morphometrics of the waters, it showed that the lake was not suitable for capture fisheries, although the local government has rehabilitated fish population by means of restocking and establishment of fish protection zones. Therefore, alternatives of fisheries management are needed, such as developing fish culture in floating net cages or fisheries recreation.

KEYWORDS: Fishery resource management, Lake Toba.

\section{PENDAHULUAN}

Danau Toba merupakan salah satu perairan umum yang dimanfaatkan oleh banyak sektor, baik pariwisata, perikanan, energi maupun perhubungan. Salah satu dampak pemanfaatan negatif adalah pemanfaatan terhadap ikan batak (Neolissochilus sp.) yang keberadaannya di

" Peneliti pada Balai Penelitian Perikanan Aır Tawar 
Danau Toba pada saat ini sudah mulai terancam kelestariannya (Kottelat et al., 1993). Seperti kita ketahui jenis ikan tersebut digunakan dalam upacara adat sehingga mempunyai nilai sosialekonomi yang tinggi. Di lain pihak usaha peningkatan dan pengembangan kepariwisataan di danau ini akan lebih mendorong peningkatan pelestarian budaya setempat. Sebaiknya upaya tersebut harus diikuti dengan usaha pelestarian sumber daya perairannya.

Sasaran program pengelolaan suatu badan air (danau ataupun waduk) kebanyakan dibuat oleh pemegang kebijakan atau penguasa badan air tersebut. Walaupun demikian peran peneliti cukup penting dalam menentukan kondisi yang paling optimum dari fungsi ekosistem tersebut (Clark, 1974). Sejalan dengan ini, usaha pengelolaan perikanan Danau Toba perlu didukung oleh hasil penelitian, sehingga penerapan teknologi pengelolaan sumber daya perikanan di danau tersebut akan berdayaguna dan berhasil guna.

Tujuan penelitian ini adalah untuk mendapatkan data potensi perairan dan alternatif pengelolaan sumber daya perikanan (pengelolaan populasi dan konservasi) di Danau Toba, sebagai suatu masukan untuk penyusunan paket teknologi pengelolaan sumber daya perikanan yang rasional dan berwawasan lingkungan.

\section{BAHAN DAN METODE}

Penelitian ini dilakukan di Danau Toba yang meliputi Kabupaten Tapanuli Utara, Dairi, Karo dan Simalungun. Penelitian dilakukan tiga kali selama tahun 1994-1995, yaitu pada musim peralihan (Februari), kemarau (Agustus), dan musim hujan (November).

Metode yang dipakai dalam penelitian ini adalah metode survai dengan pengambilan sampel strata (Parel et al., 1973). Sedangkan pembagian stasiun pengamatan berdasarkan jenis pemanfaatan perairan tersebut, seperti daerah budidaya ikan (Simanindo, Panahatan, Tigaras, Muara), perikanan tangkap (Pangururan, Palipi, Bakara, Asahan), dan wisata (Prapat, Ambarita dan Tongging) (Gambar 1). Pada masing-masing stratum dilakukan pengamatan terhadap kualitas lingkungan serta karakteristik populasi ikan (Wedepohl et al., 1990; Olem \& Flock, 1990). Variabel kualitas perairan yang diamati meliputi suhu air, $\mathrm{pH}$, alkalinitas, $\mathrm{CO}_{2}$,
$\mathrm{O}_{2}, \mathrm{Fe}, \mathrm{N} \cdot \mathrm{NO}_{2}, \mathrm{~N} \cdot \mathrm{NO}_{3}, \mathrm{~N} \cdot \mathrm{NH}_{4}, \mathrm{SO}_{4}, \mathrm{P} \cdot \mathrm{PO}_{4}, \mathrm{Ca}$, $\mathrm{Mg}$, BOT dan plankton. Pengambilan sampel plankton dilakukan dengan jalan menyaring $5 \mathrm{~L}$ air danau dengan plankton net no. 25. Pengamatan plankton meliputi jenis, kelimpahan dan keragaman untuk masing-masing stasiun pengamatan. Analisis keragaman plankton didasarkan pada Indeks Keragaman Shannon - Wienner (Magurran, 1988). Rumus keragaman yang digunakan adalah:

$$
D=p_{i} \log _{2} p_{i}
$$

di mana: $\mathrm{D}=$ keragaman dan $\mathrm{p}_{\mathrm{i}}=$ proporsional kelimpahan jenis plankton ke-i. Selanjutnya variabel kualitas perairan tersebut dianalisis dengan menggunakan analisis komponen utama.

Pengamatan karakteristik populasi ikan meliputi kebiasaan makan, luas relung makan, tingkat kematangan gonad dan faktor kondisi. Kebiasaan makan dianalisis dengan menggunakan metode indeks preponderan (Natarajan \& Jhingran dalam Effendie, 1979) yaitu:

$$
I_{i}=\frac{V_{i} O_{i}}{\sum V_{i} O_{i}} \times 100 \%
$$

di mana: $I_{i}=$ indeks preporderan pakan ke-i, $V_{i}=$ persentase volume pakan ke-i dan $\mathrm{O}_{\mathrm{i}}=$ persentase kejadian pakan ke-i. Luas relung pakan dianalisis dengan menggunakan Indeks Levin yang didasarkan pada informasi data kebiasaan makan (Hespenheide, 1975):

$$
B=\left(\sum p_{i}^{2}\right)^{-1}
$$

di mana: $B=$ luas relung makan dan $p_{i}=$ proporsional jenis pakan ke-i yang dikonsumsi. Faktor kondisi dianalisis berdasarkan informasi data panjang dan bobot ikan, dengan mempergunakan rumus Bolger \& Connolly (1989):

$$
W=a L^{b}
$$

di mana: $\mathrm{W}=$ bobot ikan, $\mathrm{L}=$ panjang ikan, a dan $\mathrm{b}=$ konstanta. Tingkat Kematangan Gonad (TKG) ikan betina ditentukan berdasarkan sifatsifat morfologi dan histologi gonad, sebaran diameter telur serta sifat-sifat telur. Semua data dianalisis dengan menggunakan Quatro Pro, Fisat dan Statgraphics. 


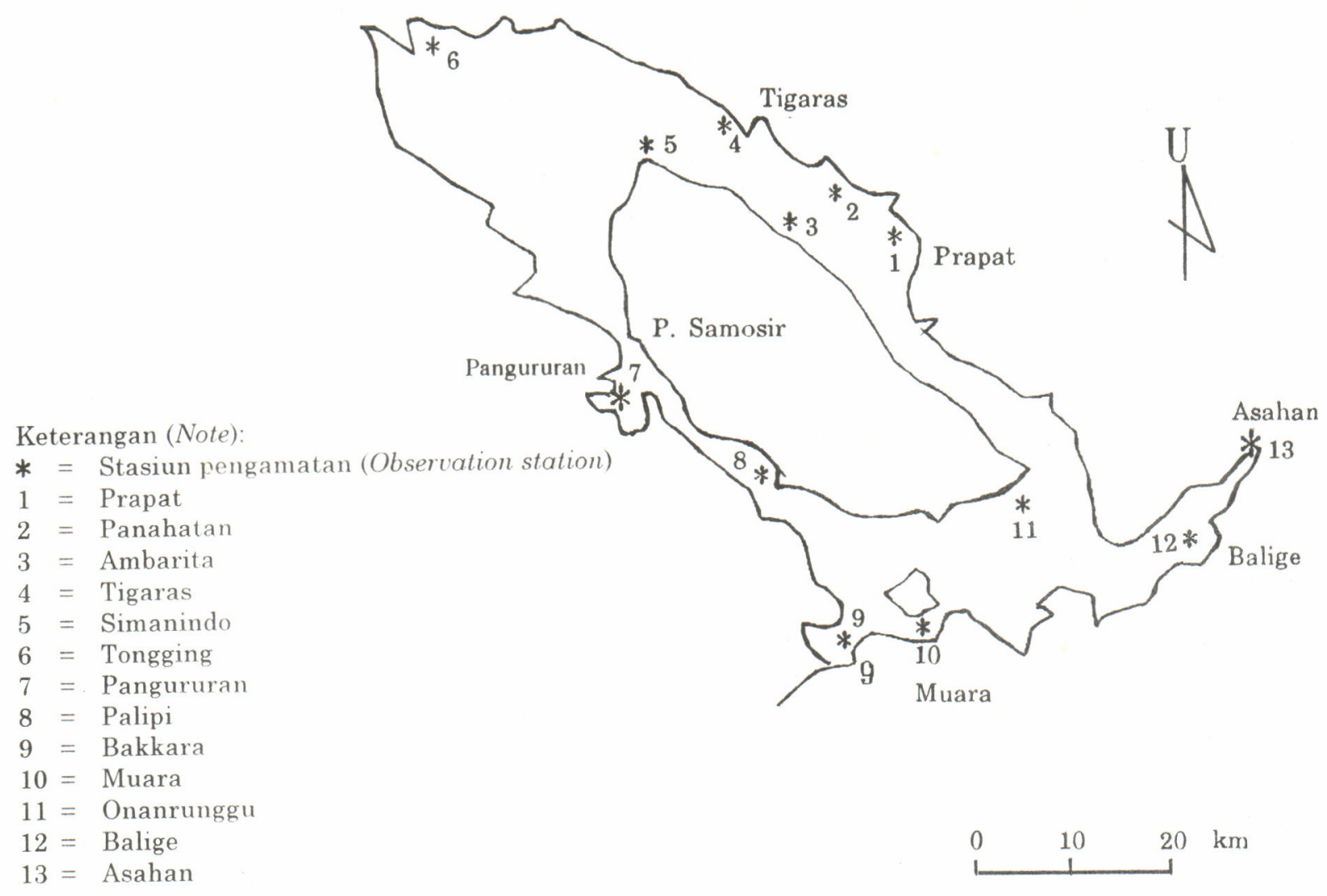

Gambar 1. Danau Toba dan stasiun pengamatan.

Figure 1. Lake Toba and observation stations.

\section{HASIL DAN PEMBAHASAN}

\section{Keadaan Umum Perikanan Danau Toba}

Danau Toba yang terletak $955 \mathrm{~m}$ di atas permukaan laut adalah danau terluas di Indonesia $\left(1129,7 \mathrm{~km}^{2}\right)$ dengan daerah tangkapan air seluas $3698,54 \mathrm{~km}^{2}$. Perairan yang luas tersebut telah cukup lama dimanfaatkan penduduk sekitarnya, di antaranya untuk kegiatan perikanan khususnya perikanan tangkap.

Beberapa daerah perairan yang dangkal merupakan daerah penangkapan seperti Simarmata, Sidabagas, Sitanggangbau, Pangururan dan Tanjungbunga. Alat tangkap yang digunakan oleh nelayan cukup beragam, di antaranya jaring (marumbuk), pancing, bubu dan tombak. Marumbuk adalah salah satu cara untuk menangkap ikan dengan melingkarkan jaring dan selanjutnya ikan dihalau ke arah jaring.
Jenis ikan yang sering tertangkap adalah mujair, nila, mas dan nilem. Pekerjaan penangkapan ikan di perairan Danau Toba hanya merupakan pekerjaan sampingan, sedang pekerjaan utamanya adalah bertani palawija. Walaupun kegiatan penangkapan ikan merupakan kegiatan sampingan, tetapi sumber daya perikanan di perairan tersebut telah memberikan sumbangan yang berarti bagi kehidupan nelayan dan petani ikan di sekitarnya. Upaya Pemerintah untuk melestarikan produksi perikanan tangkap di perairan Danau Toba dilakukan dengan dua cara, yaitu:

a) Penetapan daerah reservat sebanyak 20 buah.

b) Restoking (penebaran ulang) jenis-jenis ikan yang digemari oleh masyarakat, di antaranya ikan mas (Cyprinus carpio), nilem (Osteochilus hasseltii) dan nila (Oreochromis niloticus). Jumlah per jenis ikan yang ditebar Pemerintah dapat dilihat pada Gambar 2. 
Hasil pengamatan sifat fisika-kimia air pada tahun 1994 dan 1995 (kecuali di daerah budidaya) tidak menunjukkan perbedaan yang berarti bila dibandingkan sifat fisika kimia air hasil penelitian pada tahun 1985/1986 (Kartamihardja, 1987) dan hasil penelitian Ekspedisi Sunda yang dilakukan pada tahun 1928 (Ruttner, 1930). Hal ini menunjukkan bahwa unsur-unsur hara yang masuk ke perairan dari daerah sekitarnya seimbang dengan unsur-unsur hara yang diendapkan. Di daerah di mana terdapat usaha budidaya ikan dalam karamba apung menunjukkan kandungan nutriennya relatif lebih tinggi. Keadaan tersebut disebabkan pemasukan bahan organik ke perairan lewat sisa pakan yang diberikan pada ikan budidaya. Secara umum daerah ini mempunyai kandungan ortofosfat yang cukup tinggi, tetapi kandungan nitrogen totalnya rendah, sehingga kandungan nitrogen merupakan faktor pembatas bagi pertumbuhan dan perkembangan organisme produsen primer.

Genera fitoplankton yang dominan di perairan ini adalah Diatoma, Navicula, Protococcus, Ulothrix dan Synedra. Kepadatan plankton di masing-masing stasiun pengamatan berkisar antara 293-1855 ind/L, di mana stasiun pengamatan yang mempunyai kepadatan plankton terendah adalah Prapat yang merupakan pusat daerah wisata di perairan tersebut. Kelimpahan plankton yang relatif tinggi dijumpai di daerah Asahan, Palipi, Ambarita, Balige dan Tigaras (Tabel 2). Pada umumnya daerah yang ada kegiatan budidaya ikannya, kelimpahan dan keragaman planktonnya relatif lebih tinggi. Berdasarkan kepadatan planktonnya, Danau Toba termasuk perairan oligotrofik. Hasil penelitian ini agak berbeda dengan hasil penelitian Kartamihardja pada tahun 1985-1986 yang menunjukkan bahwa komunitas plankton di perairan ini didominasi oleh Straurastum, Microcystis, Botryococcus, Rivularia, Cymbella dan Cyclops. Perbedaan tersebut mungkin disebabkan oleh pengaruh musim ataupun perubahan komposisi nutrien yang ada.

\section{Komunitas Ikan}

Hasil pengamatan menunjukkan bahwa beberapa jenis ikan ekonomis penting yang terdapat di Danau Toba merupakan jenis ikan introduksi, seperti mas (Cyprinus carpio), mujair (Oreochromis mossambicus), nila (O. niloticus) dan nilem (Osteochilus hasseltii). Hasil ini tidak berbeda dengan pengamatan Kartamihardja (1987) dan Ondara (1968) yang menyatakan bahwa komunitas ikan di perairan Danau Toba terdiri atas 14 jenis, yang sebagian besar merupakan jenis ekonomis penting. Adapun jenis ikan yang sering tertangkap oleh nelayan adalah mujair, nila, nilem, mas dan sepat (Gambar 3). Ikan batak (Neolissochilus sp.) merupakan salah satu jenis ikan asli Danau Toba yang populasinya telah mulai langka (kurang dari 5\%). Menurut masyarakat setempat menurunnya populasi ikan batak disebabkan adanya upaya introduksi ikan mujair dan mas. Namun berdasarkan hasil analisis kebiasaan makannya, tumpang tindih dari kebiasaan makan ikan-ikan tersebut dalam memanfaatkan sumber daya makanan alami relatif tidak besar (Tabel 3), sehingga kompetisi makanan antar jenis ikan tersebut tidak terlalu besar. Berdasarkan pemanfaatan makanan alami maupun habitat, ikan mujair lebih unggul baik dalam luas relung maupun kompetisinya dibandingkan dengan ikan mas. Keadaan ini yang menyebabkan ikan mas tidak dapat berkembang di Danau Toba, walaupun telah dilakukan penebaran atau restoking ikan mas dalam jumlah yang cukup besar (rata-rata 147.000 ekor/tahun).

Ikan sepat siam, yang memanfaatkan detritus dan fitoplankton, mempunyai luas relung makan yang sangat sempit, serta mempunyai daerah sebaran yang terbatas (banyak dijumpai di daerah Tongging). Ikan nila mempunyai luas relung makan yang paling luas di antara ke-6 jenis ikan tersebut di atas, dan mempunyai daerah sebaran yang tidak luas, yaitu di daerahdaerah yang relatif landai dan dangkal. Dibandingkan dengan ikan mujair yang mempunyai sebaran yang lebih luas dan luas relung makan yang lebih sempit, ikan nila lebih unggul karena ikan nila lebih mampu memanfaatkan pakan yang ada. Keadaan tersebut juga ditunjukkan oleh tingkat kegemukan atau kemontokan ikan, yang dapat dilihat dari hubungan panjang-bobot ikan-ikan tersebut, sebagai berikut:

$$
\begin{array}{ll}
\text { - untuk ikan nila } & : \mathrm{W}=-1.59 \mathrm{~L}^{2.825}(\mathrm{r}=98.6 \%) \\
\text { - untuk ikan mujair } & : \mathrm{W}=-0.63 \mathrm{~L}^{1.963}(\mathrm{r}=72.9 \%)
\end{array}
$$

di mana: $\mathrm{W}=$ bobot ikan dan $\mathrm{L}=$ panjang ikan

Kematangan gonad dan pengukuran diameter telur hanya dilakukam untuk ikan mujair dan nila, karena kedua jenis ikan tersebut yang telah 
Jurnal Penelitian Perikanan Indonesia Vol.IV No.1 Tahun 1998

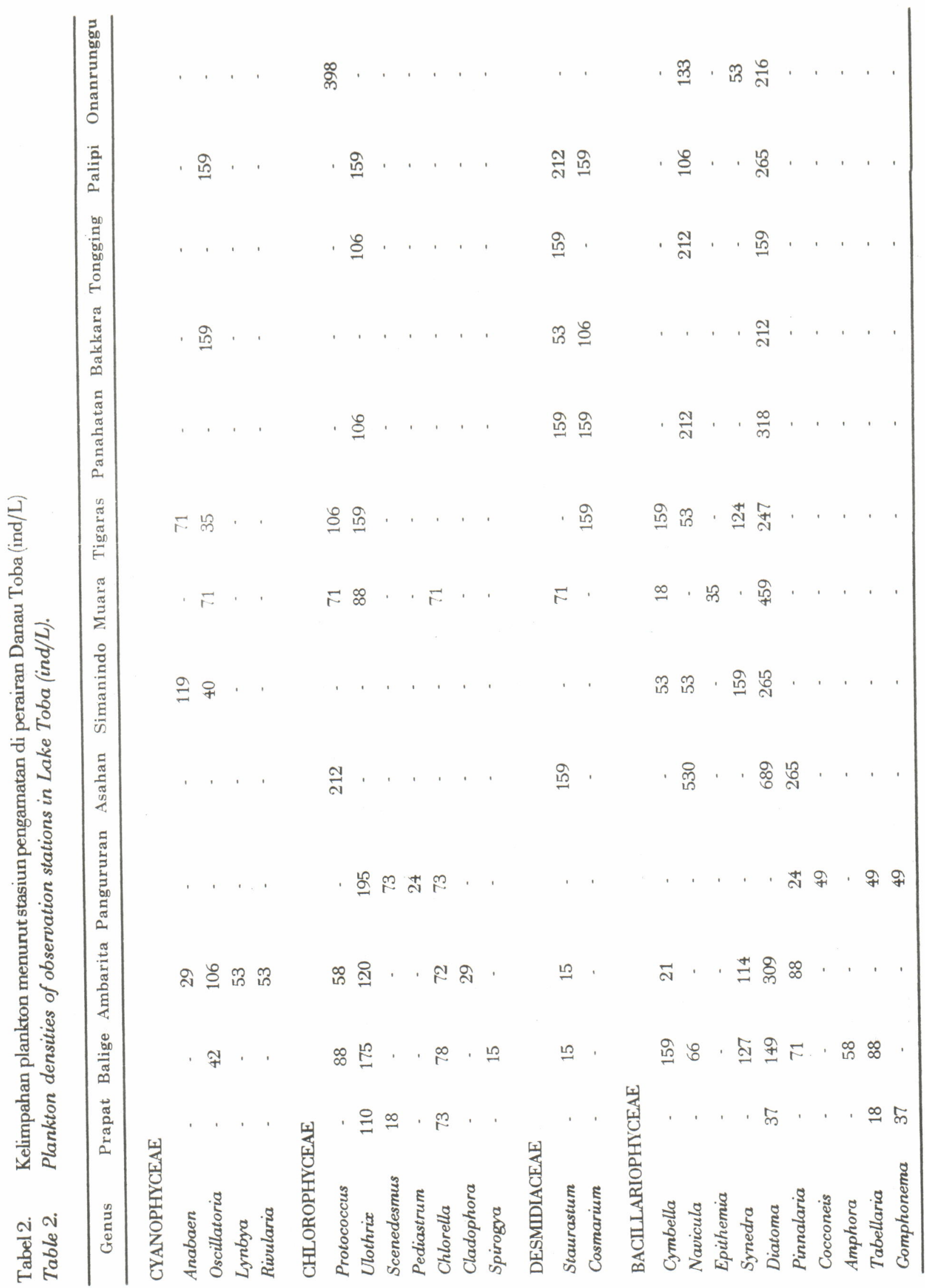


Tjahjo, D.W.H.; Adriani, S.N.; Kunto, P.; Endi, S.K.; dan Achmad, S.S.

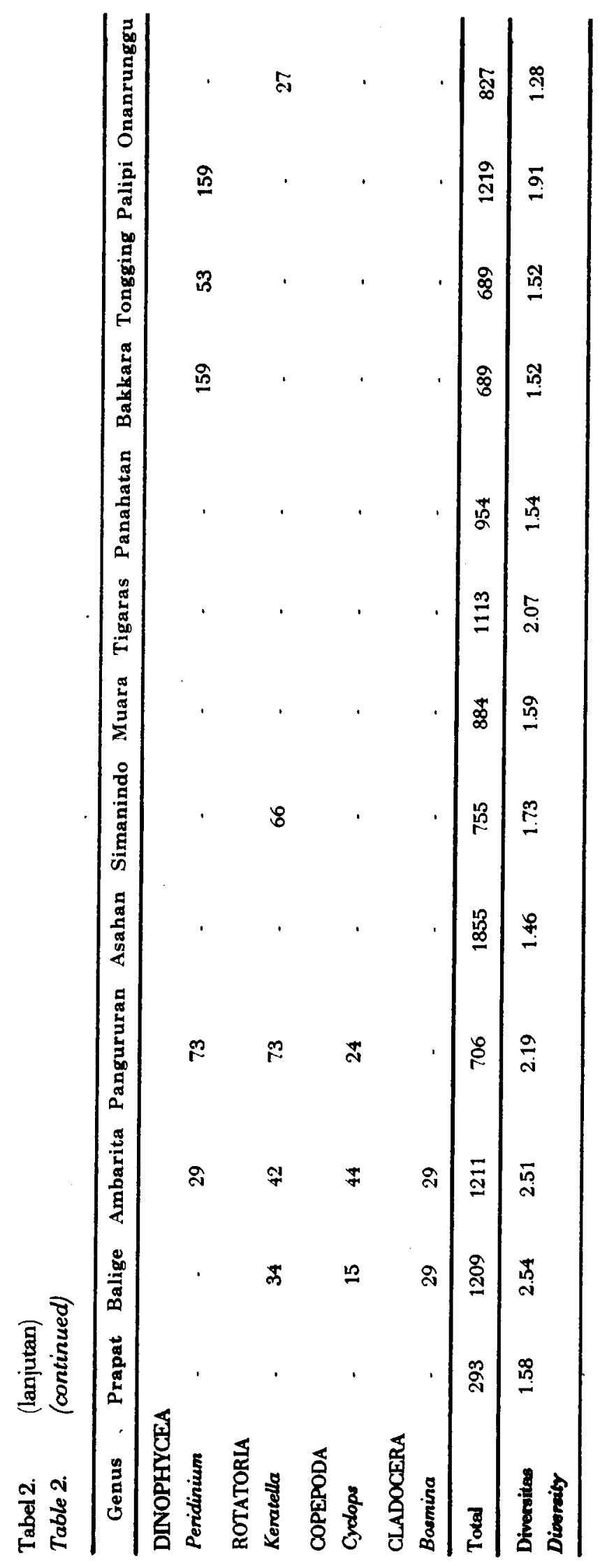




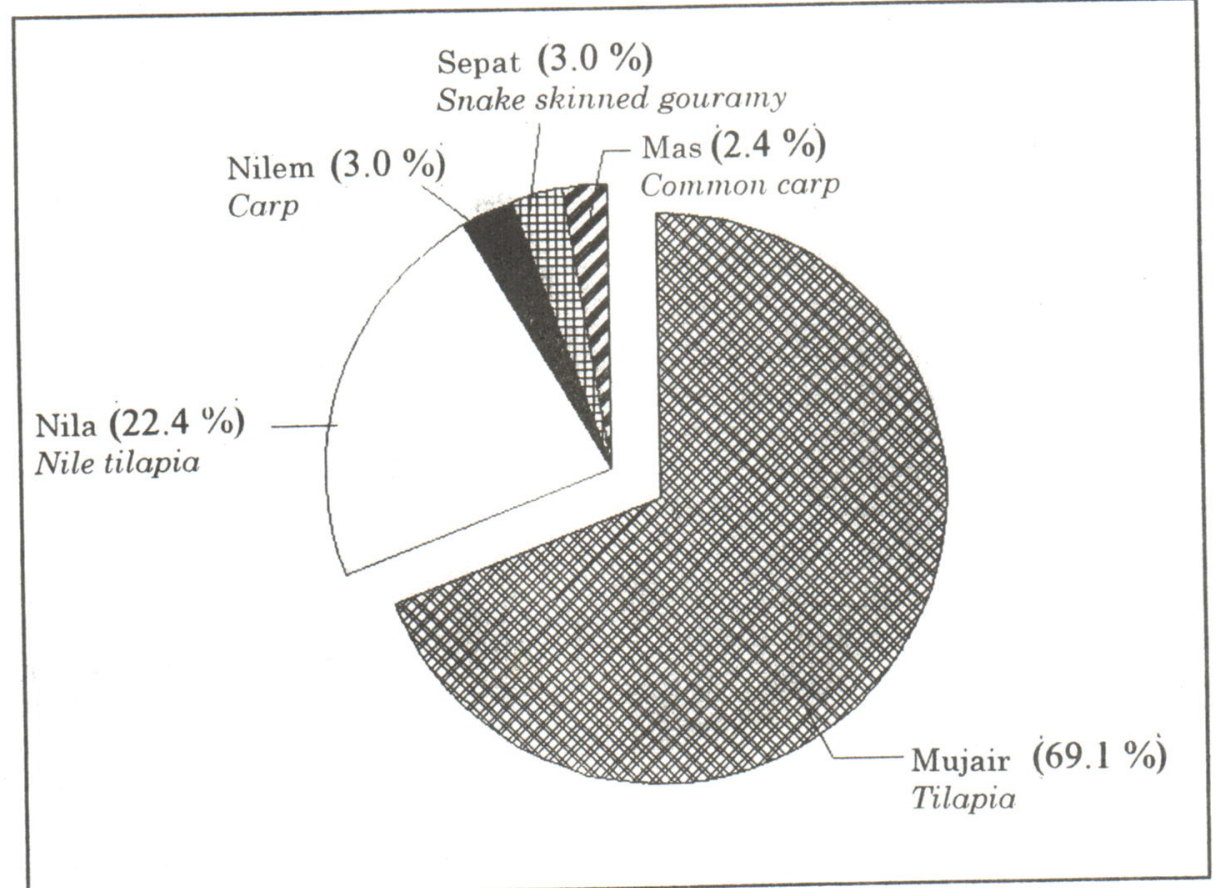

Gambar 4. Komposisi jenis ikan yang ditangkap oleh nelayan.

Figure 4. Composition of fish species caught by fishermen.

Tabel 3. Kebiasaan makan dan luas relung pakan ikan mujair, nila, nilem, mas, batak, dan sepat siam. Table 3. Food habit and niche breadth of tilapia, nile tilapia, carp, common carp, batak carp, and snake skinned gouramy.

\begin{tabular}{|c|c|c|c|c|c|c|}
\hline \multirow{2}{*}{$\begin{array}{c}\text { Makanan alami } \\
\text { Natural food } \\
(\%)\end{array}$} & \multicolumn{6}{|c|}{ Jenis ikan (Fish species) } \\
\hline & $\begin{array}{l}\text { Mujair } \\
\text { Tilapia }\end{array}$ & $\begin{array}{l}\text { Nila } \\
\text { Nile } \\
\text { tilapia }\end{array}$ & $\begin{array}{c}\text { Nilem } \\
\text { Carp }\end{array}$ & $\begin{array}{c}\text { Mas } \\
\text { Common } \\
\text { carp }\end{array}$ & $\begin{array}{c}\text { Batak } \\
\text { Batak } \\
\text { carp }\end{array}$ & $\begin{array}{c}\text { Sepat } \\
\text { Snake skinned } \\
\text { gouramy }\end{array}$ \\
\hline Detrius & 29.24 & 22.47 & 11.25 & 30.00 & 41.36 & 74.83 \\
\hline $\begin{array}{l}\text { Makrofita akuatik } \\
\text { Aquatic macrophyta }\end{array}$ & 31.75 & 33.21 & 54.58 & 20.00 & - & - \\
\hline $\begin{array}{l}\text { Fitoplankton } \\
\text { Phytoplankton }\end{array}$ & 38.82 & 37.82 & 34.17 & - & 48.85 & 25.17 \\
\hline Zooplankton & 0.01 & - & - & - & 6.25 & - \\
\hline Insekta (Insects) & - & - & - & - & 3.54 & - \\
\hline Moluska (Molluscs) & - & - & - & 50.00 & - & \\
\hline Udang (Shrimps) & - & 6.50 & - & - & - & - \\
\hline $\begin{array}{l}\text { Luas relung pakan } \\
\text { Niche breadth }\end{array}$ & 3.67 & 4.24 & 2.43 & 2.63 & 2.64 & 1.74 \\
\hline
\end{tabular}


berkembang. Hasil pengamatan tingkat kematangan gonad ikan mujair dan ikan nila menunjukkan bahwa pada bulan Agustus 1994, gonad ikan-ikan tersebut masih dalam tahap perkembangan (TKG II dan III). Pada bulan November 1994 jenis-jenis ikan ini berada pada TKG IV atau siap untuk memijah. Diduga kedua jenis ikan ini memijah pada awal musim hujan, yaitu sekitar bulan November 1997 sampai Januari 1995. Hal ini di dukung oleh hasil tangkapan pada bulan Februari 1995, di mana untuk kedua jenis ikan ini selain ditemukan TKG IV juga ditemukan TKG $\mathrm{V}$, yaitu telah memijah (spent). Hasil analisis perkembangan diameter telur menunjukkan bahwa ikan nila maupun ikan mujair memijah sebanyak satu kali dalam satu musim pemijahan. Diameter telur ikan nila yang siap untuk dikeluarkan berkisar antara 0,98-1,31 mm dan untuk ikan mujair berkisar antara 0,8125 $1,8750 \mathrm{~mm}$.

Potensi perikanan Danau Toba yang diduga dari produktivitas primernya (diukur di daerah Prapat dan Pangururan), berkisar antara 5,84$30,95 \mathrm{~kg} / \mathrm{ha} /$ tahun dengan rata-rata $10,66 \mathrm{~kg} / \mathrm{ha} /$ tahun. Potensi tersebut relatif sama dengan hasil penelitian Kartamihardja pada tahun 1985-1986 yaitu 6-24 kg/ha/th. Hal tersebut menunjuk-kan bahwa potensi produksi danau stabil karena perairan ini mempunyai kedalaman air yang sangat dalam dan bersifat oligotrofik.

\section{Pengelolaan Perikanan}

Pengelolaan perikanan yang ditujukan untuk meningkatkan produksi ikan di perairan umum (danau dan waduk) meliputi tiga kategori, yaitu manipulasi habitat, pengelolaan populasi ikan dan orgnisme makanan alami, dan pengelolaan pemanfaatannya. Di Danau Toba, pengelolaan perikanan seyogyanya ditujukan tidak hanya untuk meningkatkan produksi ikannya, melainkan juga untuk melindungi dan melestarikan ikan batak.

Jenis ikan yang cocok dikembangkan dalam rangka meningkatan produksinya adalah jenis ikan yang mampu menyesuaikan diri terhadap morfologi perairan danau tersebut, yaitu ikan nila dan mujair. Sedangkan ikan mas yang dewasa ini menjadi harapan Pemeritah Daerah, kurang mampu berkembang dengan baik di perairan yang miskin makanan alami, curam dan sangat dalam serta mempunyai kompetisi antar jenis ikan yang sangat tinggi.
Langkah pengelolaan perikanan di Danau Toba yang diharapkan dapat meningkatkan produksinya dan melindungi ikan langka (termasuk ikan batak) adalah:

1. Tata ruang pemanfaatan sumber daya perikanan. Tata ruang ini harus mempertimbang. kan tingkat kesuburan dan morfologi perairan Danau Toba, serta keberadaan ikan batak. Untuk itu, tata ruang yang sesuai bagi Danau Toba adalah sebagai berikut:

- mintakat konservasi (meliputi daerah muara Sungai Bakara dan Asahan) yang ditujukan untuk perlindungan ikan batak.

- mintakat pemanfaatan terbatas merupakan daerah penyangga mintakat konservasi dan merupakan daerah pemijahan dan asuhan bagi jenis ikan lainnya. Di daerah ini perlu diadakan pembatasan alat-alat tangkap yang boleh beroperasi dan pengaturan ukuran dan jenis alat tangkap.

mintakat bebas, merupakan daerah yang dapat dimanfaatkan secara bebas (Gambar 4).

2. Penebaran benih ikan dan pakan alami secara kontinyu. Pemerintah lewat Dinas Perikanan setempat telah berusaha melakukan penebaran ikan setiap tahun, akan tetapi yang banyak ditebar ikan mas bukan ikan nila yang diperkirakan lebih mampu tumbuh dan berkembang di Danau Toba dibandingkan ikan mas. Hal tersebut disebabkan ikan nila merupakan pemakan plankton dan lebih bersifat pelagis dibandingkan ikan mas yang omnivora. Sedangkan untuk pakan alami ikan dapat dilakukan penebaran jenis zooplanton, agar mampu meningkatkan produksi ikannya.

Karena secara alami potensi produksi ikan di Danau Toba rendah, pengembangan perikanan tangkap di perairan ini kurang menguntungkan dan kurang mampu meningkatkan taraf hidup masyarakat di sekitar perairan, maka perlu alternatif pemecahan. Usaha budidaya ikan dalam karamba jaring apung (KJA) dan wisata perikanan merupakan alternatif lain yang lebih menguntungkan dalam pengembangan perikanan di perairan Danau Toba. Usaha budidaya ikan dalam KJA dapat dilakukan sepanjang pantai perairan ini, kecuali di daerah wisata (seperti Parapat, Ajibata dan Tomok) dan daerah sumber belerang di Pangururan. Di daerah-daerah wisata 
dapat dikembangkan wisata perikanan, berupa proses budidaya ikan dalam KJA dan pemancingan. Walaupun demikian, dalam pengembangan usaha budidaya ikan dan wisata perikanan perlu ditetapkan tata ruang secara terpadu dengan sektor-sektor lain yang terkait. Hal tersebut diperlukan untuk menghindari konflik antar sektor, mencapai tingkat produksi yang optimum, dan untuk melestarikan fungsi danau dan sumber daya genetiknya, sehingga dapat meningkatkan pendapatan mayarakat sekitarnya secara optimal.

\section{KESIMPULAN}

Berdasarkan kandungan nutrien dan morfometriknya, Danau Toba termasuk tipe perairan oligotrofik.
Berdasarkan karakteristik biologi ikan yang ada (kebiasaan makan, luas relung dan reproduksinya), kesuburan perairan dan morfometrik perairan, danau ini kurang mendukung untuk usaha perikanan tangkap, walaupun pemerintah telah melakukan rehabilitasi stok ikan melalui penebaran ulang dan penetapan daerah reservat. Hal tersebut disebabkan adanya faktor pembatas dalam peningkatan produktivitas perairan, yaitu miskinnya akan unsur hara, kecuraman pantai dan kedalamannya.

Mengingat peluang untuk pengembangan perikanan tangkap sangat kecil, maka perlu alternatif pengembangan usaha perikanan lainnya yang lebih menguntungkan, yaitu usaha budidaya ikan dalam keramba jaring apung dan wisata perikanan.

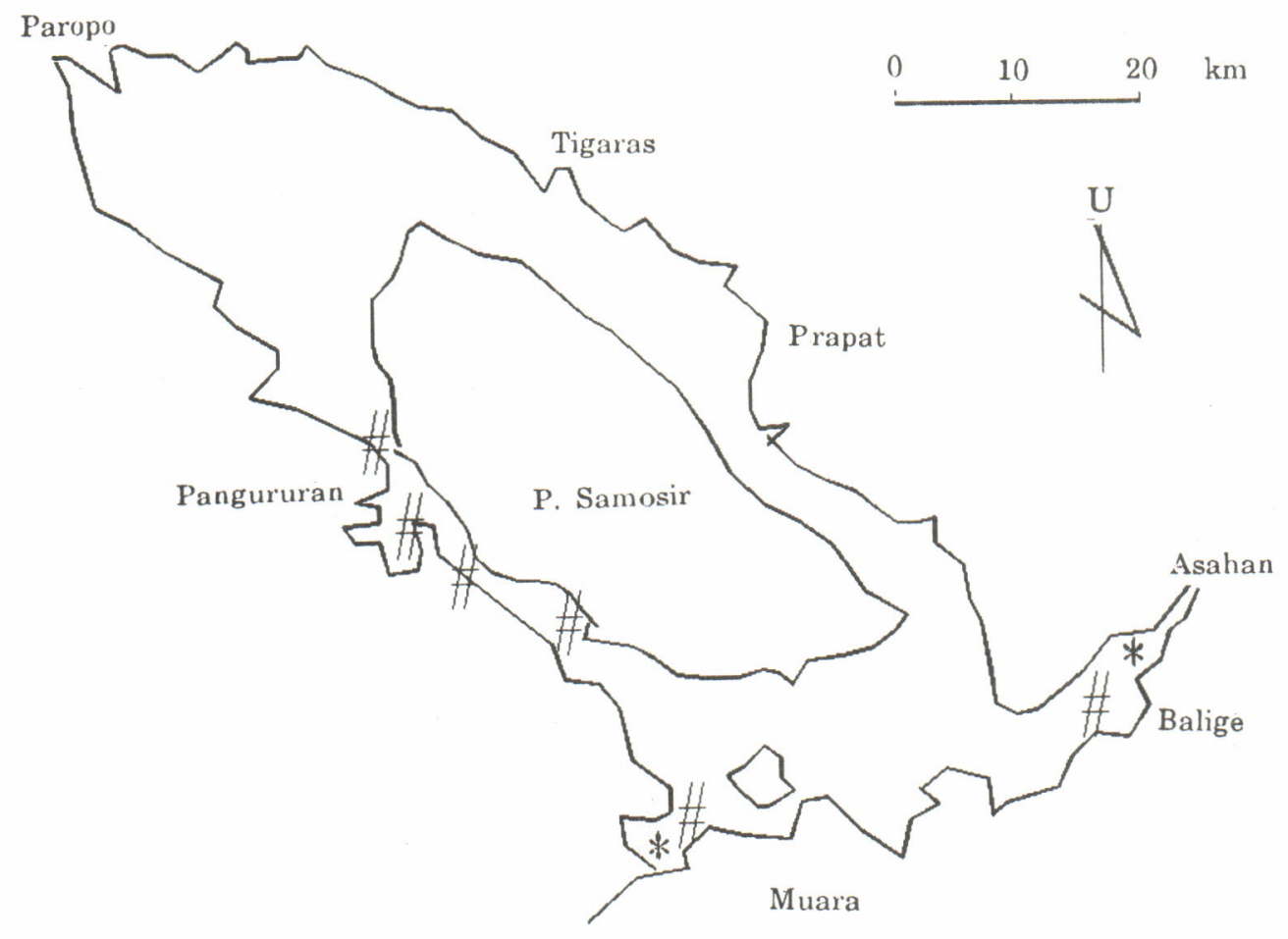

Keterangan (Note):

* = Daerah reservat (Conservation area)

\# = Pemanfaatan terbatas (Limited utilization)

Gambar 4. Tata ruang perikanan di Danau Toba.

Figure 4. Fisheries zonation in Toba Lake. 
Tjahjo, D.W.H.; Adriani, S.N.; Kunto, P.; Endi, S.K.; dan Achmad, S.S.

\section{DAFTAR PUSTAKA}

Bolger, T. and P.L. Connolly. 1989. The selection of suitable indices for the measurement and analysis of fish condition. J. Fish Biol. 34: 171-182.

Clark. 1974. Coastal ecosytems: ecological considerations for management of the coastal zone. The Conservation Foundation, Washington, D.C

Effendie, M.I. 1979. Metode biologi perikanan. Yayasan Dewi Sri, Bogor. 112 p.

Hespenheide, H.A. 1975. Prey characteristics and predator niche width. In Cody, M.L. and J.M. Diamond (eds.) Ecology and evolution of communities. The Belknap Press of Harvard Univ. Press, London. p. 158-180.

Kartamihardja. 1987. Potensi produksi dan pengelolaan perikanan di Danau Toba, Sumatera Utara. Bull. Penel. Perik. Darat 6(1).

Kottelat, M., A.J. Whitten, S.N. Kartikasari and S. Wiroatmodjo. 1993. Freshwater fishes of Western Indonesia and Sulawesi (Ikan air tawar Indonesia bagian Barat dan Sulawesi). Periplus Editions Ltd. Indonesia.

Magurran, A.E. 1988. Ecological diversity and its measurement. Princeton University Press, New Jersey. 179 p.
Olem, H. and G. Flock (eds). 1990. Lake and reservoir restoration guidance manual. 2nd edition. EPA 440/4-90-006. Prep. by N. Am. Lake Manage. Soc. for U.S. Environ. Prot. Agency, Washington, DC.

Ondara. 1968. Survey perikanan di Danau Toba (Sumatera Utara). Laporan no. 6, Lembaga Penelitian Perikanan Darat, Bogor.

Parel, C.P., G.C. Caldito, P.L. Ferrer, G.G Guzman, C.S. Sinsioco and R.H. Tan. 1973. Sampling design and procedures. The Agricultural Development Council, New York.

Ruttner, F. 1930. Hydrographische un hydrochemische Beobachtungen auf Java, Sumatra und Bali. In Thienemann, A. (ed.) Archiv fu Hydrobiologie. Stuttgart. p. 197-454.

Wedepohl, R.E., D.R. Knauer, G.B. Wolbert, H. Olem, P.J. Garrison and K. Kepford. 1990. Monitoring lake and reservoir restoration. EPA 440/4-90-007. Prep. by N. Am. Lake Manage. Soc. for U.S. Environ. Prot. Agency, Washington, DC.

Welch, P.S. 1952. Limnology. McGraw-Hill Book Company, Inc. $538 \mathrm{p}$

Wetzel, R.G. and G.E. Likens. 1979. Limnological analysis. W.B. Saunder Co. London. $357 \mathrm{p}$. 